\title{
Urban Typography as a Reflection of Talkative Behavior in Malang City
}

\author{
Susilo Kusdiwanggo ${ }^{1 *}$, Chairil B. Amiuza ${ }^{2}$ \\ ${ }^{1,2}$ Department of Architecture, Faculty of Engineering, Universitas Brawijaya, Malang, Indonesia. \\ *Corresponding author. Email: kusdiwanggo@ub.ac.id
}

\begin{abstract}
There is a phenomenon of large sign letters presence in almost all cities in Indonesia at present to mark names of places that are already known by the public, including Malang City. This trend shows that there seems to be a contagion that infects one city to another without apparent reason. This mimetic phenomenon represents bad talkative behavior. Large or monumental letters assembled into one striking word as a sign (signage) of a place. Urban signage should be able to show a structuring role by building a unique identity and sense of place, thus creating an image in the form of the environment. However, the presence of monumental sign letters is no longer unique when all cities are busy to imitate and become stereotypes. How to interpret the large sign phenomenon as urban-talkative on architectural populism in the context of semiotics? This study aims to interpret the phenomenon of urban space typography design through semiotics from the pragmatism paradigm based on the first semiosis process of interpretant pole in Malang City. This research uses pragmatism, deductive and mixed-method methods. The research results indicate that the process of interpretant affirmation from the level of secondness to thirdness occurs in three ways; (1) not linear, (2) cross, and (3) linear. Not linear affirmations indicate the problem of communication between public institutions and citizen as interpretant. Cross affirmations indicate that interpretants tend (1) to look at accompanying elements of typography rather than the typography itself and (2) encourage typography as a city identity. Whereas linear affirmations indicate that (1) the presence of urban typography is a talkative behavior and becomes a problem of urban psychology and (2) interpretants tend to look urban typography in terms of subfunctions or content rather than the design of the typography itself.
\end{abstract}

Keywords: First semiosis, pragmatics, semiotic, typography, urban

\section{INTRODUCTION}

Large signs on buildings in a city reminiscent of an essay written by Robert Venturi about Las Vegas in the late 1970s [1]. Likewise, Vinegar [2] calls these large signs letters with the term 'big sign on top blinking (big wink)' in his critical caricature: 'I am a monument'. In another critical review, these can be categorized as architectural populism [3]. What is presented is part of the Postmodern movement. However, all these things have happened in the past $[4,5,6,7]$.

There is a phenomenon of large sign letters presence in almost all cities in Indonesia at present. The signs are present to mark names of places that are already known by the public. In some city corners and certain other places, even in an educational area, which is categorized as a public space, there will be big sign letters posted. This trend was started by a city (another), then spread and infect other cities. Apart from economic-political intrigue, one of which becomes a kind of project for goods and services procurement, this trend is an indication that there has been an event of extraction from one urban institution followed by other urban institutions without apparent reason. These mimetic processes represent talkative behavior.
Talkative usually occurs personally, but with the symptoms above, it turns out that talkative is not only in a personal verbal form with the symptoms above, but it can also massively touch urban-institutional. In the talkative behavior, both personal and institutional interests follow a trend without knowing the reason for doing it. It seems like urban behavior that moves distortively.

In the urban context, talkative is a unique condition in which urban-institutionals indicate changes in awareness and abnormalities quality of suggestibility level. The talkative city will repeat words (echolalia) or certain actions (echopraxia) from its neighboring city - this kind of urban shows inappropriate social behavior. Urbantalkative is a disorder or disease that must be treated.

Urban-talkative occurs due to the repression of internal conflicts within an urban, resulting in attracting attention and fighting its subordinate position. Cities with urban talkative behavior exhibit certain symbolic meanings in specific cultural areas. It is just not certain yet which cultural areas are trodden (urban-talkative understanding modified from Kompasiana [8]).

Letters which are categorized as large typography are intended to provide information and/or elements of urban sculpturist. The series of letters is present as a linguistic which can be partly a part of communication theory or 
significance. The term communication usually refers to the use and influence of a sign system. Meanwhile, the terms signification refers to properties, internal relations, and rules that control the sign system.

From the perspective of pragmatism (Peirce), signs that are factually present are forms of reality and can build meaning. The forming of the meaning process involves three elements. They are the first symptom, in which quality can or may appear as a sign; the second symptom means the sign actually (here and now); the third symptom when the sign has become a generally accepted fact in society (consensus). Among these three symptoms, the forming of the meaning process (semiosis) occurs in two poles, namely semiosis at interpretant pole and semiosis at representamen (sign) - object. The first semiosis is commonly referred to as the process of forming interpretant, which involves habit, belief, doubt, and a series of abduction - deduction - induction. Whereas the second semiosis is often referred to as the exploration of relations between two triadic elements, they are between sign - object (dyadic) in the cultural domain of interpretant - sign - object (triadic). Both two processes of semiosis can be studied separately.

This research examines the semiosis problem in the first stage. In the first stage of semiosis, it starts from the doubt stage, which will shake up belief and habit. Afterward, the logical argumentation process takes place in the abduction - deduction - induction stage. The first stage of abduction is to get a tentative idea as a possibility. The second stage is deduction, the process of reasoning validity because it is supported by logical consequences. The third stage of induction is the process of reasoning validity due to practical consequences in society. In the end, this pragmatic semiosis becomes an epistemology which obtains validity, not through the correspondence truth theory, but because it is supported pragmatically in a specific reality [9].

Large or monumental letters assembled into one striking word as a sign (signage) of a place. Urban signage should be able to show a structuring role by building a unique identity and sense of place, thus creating an image in the form of the environment [10]. However, the presence of monumental sign letters is no longer unique when all cities are busy copying and become stereotypes.

Is actually writing (sign letters) names of a large-scale place effective? Is this an imaging movement of a city? Is it a political identity of a city? Or is it just a photo gathering place? Whatever it is, the presence of large sign letters has become a fact in urban public spaces in Indonesia. Its presence has plagued like a disease and become a talkative phenomenon for urbanities in Indonesia, Malang City is no exception. How to interpret the large sign phenomenon as urban-talkative on architectural populism in the context of semiotics?

How to find the meaning of urban space typography design using semiotic from a pragmatic paradigm based on the semiotic process of interpretant pole? This study aims to interpret the phenomenon of urban space typography design through semiotics from a pragmatic paradigm based on the first semiosis process of interpretant pole in Malang City.

\section{RESEARCH METHODS}

This research uses the pragmatism paradigm. Research based on pragmatism paradigm includes an understanding of effects from respondent or participant actions, centered on urban typography problem, pluralistic, and real-world oriented. This research method is deductive.

This research design uses a descriptive mix-method approach in exploring the meaning of audience and understanding interpretant of a series of large sign letters phenomenon in urban space. Qualitative is needed to explore citizen ideas through field observations in open question mode. Quantitative is needed when the results of this exploration are codified in such a way as to compile and get the core of the questionnaire in closed question mode. Descriptive is used in describing background details or contextuality of the audience to an urban environment that has been penetrated by the environmental typography phenomenon. This research involves respondents in a purposive field observation and survey respondents randomly to approach the requirements of the sample amount in population.

The research data is collected by interviewing, observing, and documenting and/or taking notes in the field, which purely are primary data. Data that has been collected will produce a categorization that will be used at the survey stage. Interviews are conducted in an unstructured and tiered manner. Interview respondents cannot be done in a rigid schedule. Interviews can be done anywhere and anytime (opened questions). Each respondent will be interviewed in an off condition, meaning that the second respondent is not bound by the first respondent. The main material of interviews is the element of large sign letters that are assembled into environmental identifiers. The results of coding field observation data processing will be the data source for the next field observation in the form of a questionnaire (closed questions).

Data analysis is carried out in stages, starting with qualitative data processing, continued with qualitative data collection. The analysis results will be interpreted and verified (the discussion stage) using Peirce, Morris, and Hjemslev' theoretical references simultaneously. The interpretation does not rule out the possibility of crossreference referencing with other sources. All interpretations are still within the framework of meaning understanding on the first stage of semiosis, which always involves interpretant. The final results are expected to come out labeling the research results.

\section{RESULTS AND DISCUSSION}

Data collection is carried out in stages, namely observation, unstructured interviews, and surveys. Observation data collection is carried out to determine 
locus based on typographic category representations in open public spaces, residential environments, and educational environments (Campus). Data collection through interview method (unstructured) is opened questions. This interview is conducted to obtain the basic content of a cultural domain that will be developed in closed-questions. At the stage of data collection through the survey method, the basic cultural domain is detailed using questionnaire questions.

\subsection{Interpretation of Analysis Results: Peirce}

\subsubsection{The phase of logical argumentation: habit}

The habitus process is built from the habit of people/respondents visiting the location of objects researched. The presence frequency of respondents in the objects researched is an indication of habit patterns that are carried out unconsciously. The frequency of respondents visiting the object location is very high, even without meaningful activity, indicating that this habit builds certain patterns unnoticed.

Even in a unique way, based on recorded public opinion (respondents), it can be validated that the habitual pattern of visiting a particular place without certain activities unconsciously has animal symbolicum behavior like 'cats pee in the places they pass'. Conditions like this indicate that typography is only a sign without a concept (representamen) at this stage. When the typography is anthropologically related to the human context, the typography has a concept of symbolic function. When it comes to this stage, the process of interpreting typography moves into homo semioticus. Culture is the key manifestation of typography symbolism function.

This repetitive pattern of activities (habit) will ultimately build respondents' belief from the habitual process. This process crept from the unconscious into pre-conscious at the level of belief.

\subsubsection{The phase of logical argumentation: belief}

After repeated habits done by respondents, they begin to realize (pre-consciously) that there are options of when they can do the habit. Although most respondents choose the morning time, the disparity is not quite large compared to the night time choice. It means that there is no best time preference. It shows that respondents begin to realize that the habit turned out to build a belief (pre-conscious) when respondents usually visit the typography.

\subsubsection{The phase of logical argumentation: doubt}

The process of moving habit to belief is ultimately building total awareness of respondents. However, this awareness actually makes them start to question their presence on the objects researched. Why does the typography have to be there? Why must the typographic location be visited? Are there strong reasons for them to like or dislike the typography?

Respondents begin to doubt their previous habits and belief. This doubt does not make the response return to the unconscious level, but rather to the total awareness level. At this stage, respondents realize their position as an interpretant. These doubts will ultimately result in the process of abduction, deduction, and induction, which are intertwined with twist interlocking.

In the end, based on data deduction processing in the logical argumentation phase, five cultural domains are produced; they are frequency, preference, identity, replacement, and design norms.

\subsubsection{Phase of Interpretant}

The frequency of interpretant relations to five cultural domains in the logical argumentation phase indicates that affirmations built from interpretant opinions are sometimes the opposite. In frequency cultural domain, although interpretants refer to the results of morning time using the deduction process, interpretants collectively also affirm (arguments) to the results of night time using the induction process. These affirmations can be interpreted as an expectation that typographic activities not only take place in the morning but also at night. Nighttime activities at typographic locations will generate new atmosphere and experiences.

In fact, there are two-time cross-affirmation. First, between the frequency argument level and design norms. The existence of frequency cultural domain arguments affirms design norms. Interpretants tend to see design norms that apply to accompany typographic elements stronger than the typography itself. Second, between the preference/liking level and identity arguments, interpretants tend to expect that their favorite factors in typography can be pushed into a kind of city characteristic or identity.

Stable affirmations are demonstrated by two cultural domains; they are preference-dislike and replacement. In the preference-dislike cultural domain, interpretants argue that the typography presence indicates the tendency of Malang City only to follow other cities. Malang City is considered as a city that is urban-talkative. This talkative problem in Malang urban institutions can be included in the social attitude category. Things done by Malang City in the process to follow unthinkingly: imitating and following other cities, can be categorized as a social attitude that may experience political disappointment as if without a soul. Social attitude, in general, is related to maintaining a cultural code of ethics, whether an established culture or a certain counter-cultural deviation from it. Malang City should play a role in building a unique identity and sense of place, thus creating an image in the form of the environment. However, the presence of 
monumental sign letters is no longer unique when all cities are busy to imitate, copy, and become stereotypes.

Meanwhile, in replacement cultural domain, interpretants agree that typography cannot replace existing urban landmarks. The sign letters are still positioned as a sign (signage) somewhere that is striking with the color play.

Table 1 Relation of typography and interpretant categories

\begin{tabular}{|c|c|c|c|}
\hline \multirow{3}{*}{$\begin{array}{c}\text { Typographic } \\
\text { Cultural Domains } \\
\text { Category }\end{array}$} & \multicolumn{3}{|c|}{ Interpretation of Interpretant (aware/conscious) } \\
\hline & Firstness & Secondness & Thirdness \\
\hline & Abduction Results & Deduction Results & Induction Results \\
\hline Frequency & Morning - night. & $\begin{array}{l}\text { Morning, } \\
\text { as a casual activity. }\end{array}$ & $\begin{array}{l}\text { Night, } \\
\text { evokes atmosphere. }\end{array}$ \\
\hline \multirow[t]{2}{*}{ Preference } & Like-dislike. & $\begin{array}{l}\text { Likes: } \\
\text { Dynamic city } \\
\text { Memorabilia } \\
\text { Artistic taste } \\
\end{array}$ & $\begin{array}{l}\text { Encouraged as a city } \\
\text { identity. }\end{array}$ \\
\hline & & $\begin{array}{l}\text { Dislikes: } \\
\text { Talkative } \\
\text { Not informative } \\
\text { There is no need } \\
\text { Not important }\end{array}$ & $\begin{array}{l}\text { Following trends of other } \\
\text { cities. }\end{array}$ \\
\hline Design Norms & Suitability, proportion, color. & $\begin{array}{l}\text { Accompanying element: } \\
\text { Lights }\end{array}$ & $\begin{array}{l}\text { Lights support nighttime } \\
\text { activities. }\end{array}$ \\
\hline
\end{tabular}

Source: Kusdiwanggo [11]

\subsection{Interpretation of Analysis Results: Morris}

Morris's semiotic study consists of three interrelated things, namely pragmatics, syntactic, and semantics. The basic study of signs is a pragmatic problem. The basis for the meaning study is related to semantics. Semantics will be part of pragmatics. The basis for the syntax study is the structure of the sign system. This syntax will return to semantics in such a way that between pragmatics, semantics, and syntactics is a series of tiered and closely involved, and Morris calls it a 'nest' intertwining. The process becomes infinite.

Pragmatics; with regard to the authenticity of using (with who made it) and the sign influence (on who is interpreting it) in overall for the behavior they experience. Semantics; with regard to the signs signification in overall ways of signifying them, a way which carried 'meaning'. Syntactics; with regard to signs combination (such as how words are strung together to form sentences) without regard to their specific meaning or their relationship to the behavior they experience. Related to the first semiosis process in Peirce, pragmatics are references that can be used as a research tool.

Typography is a city property. The city is the creator of the series of sign letters. But the problem that arises is how communication (not significance) can be established between city institutions and citizen (interpretant), and how the use of typography and the influence of sign systems on interpretants.
Communication becomes problematic when city institutions do not convey the purpose of urban typography presence to the citizen (interpretant). This problem can be found in opinions that develop within citizens (based on this research). Interpretants have floating opinions and are not focused because they do not know the reason for the typography presence. This condition can be shown from the affirmation process results of abduction, deduction, and induction of Peirce, where there are no linear affirmations, even crossing over. Linear affirmations actually indicate that the presence of typography is a talkative phenomenon as an urban psychological problem facing the city. Besides, the presence of typography in linear affirmations cannot be interpreted as a replacement for existing city landmarks.

If the pragmatic process does not run successfully, then it can be ascertained that the semiotic process which moves towards syntagmatic and/or semantic will be problematic and stop. Communication would not occur; meaning also would not occur.

\subsection{Interpretation of Analysis Results: Hjelmslev}

The main problem with finding affirmative discrepancies in the discussion of Peirce's interpretation is thought to be strongly related to the problem of stopped pragmatic communication. This problem arises because there is no 
communication between who made it and who interpreted it.

Hjemslev offers a model based on the difference between the level of content and the level of expression in the language system, and both are divided into subparas of form and substance. In this perspective, an architectural object (typography) can be seen as a double face unit. In terms of expression, typography consists of morphemes, which are understood as substantive architectural forms. Morpheme is a morphological characteristic of typography. In terms of content, typography consists of semems which are understood as architectural functions. Semem is a subfunction of typography.

The results of interpretant linear affirmations of design norms cultural domain indicate that the building ambience around urban typography through the presence of light elements confirms that interpretants look more at urban typography in terms of subfunction or content. Interpretants tend to see urban typography design as subfunction rather than the design of the typography itself. In the Hjemslev model, a scheme is seen that typography is related to the form of content and expression. The thing to note in this scheme is that: something behind the cultural unit is continuous with the reality of content and expression as ultimate realities.

This research is only limited to interpretant studies as the first process of semiosis. The Hjemslev model refers more to the existence of objects in the Peirce semiotic model compared to the interpretants, because of that, the Hjemslev model cannot be used totally as an interpretant study. Each content and expression have their own substance (concept). This concept itself will not appear when there is a communication problem between the creator and interpretants. Particularly in the background of content and expression, there is a cultural unit that stands as a figure who gave birth to meaning (symbols). For Peirce, symbols are part of the relationship between thirdness (induction results) and objects.

\section{CONCLUSION AND RECOMMENDATION}

\subsection{Conclusion.}

The research results indicate that the process of interpretant affirmation from the level of secondness to thirdness occurs in three ways: (1) non-linear, (2) cross, and (3) linear.

Non-linear interpretant affirmations occur in frequency and preference culture domain. At the level of thirdness, it is as an induction or reasoning process validated from practical consequences of society, whereas not linear in the process of secondness before, as a process of deduction. Not linear affirmations indicate the existence of communication problems between urban institutions and citizen as interpretant.
Cross interpretant affirmations occur between frequency culture domain design norms and between the cultural domain of preference-like with identity. Cross affirmations indicate that interpretants tend to (1) see accompanying elements of typography rather than the typography itself and (2) encourage typography as a city identity.

Linear interpretant affirmations occur in the cultural domain of preference-dislike and replacement. Linear affirmations indicate that (1) the presence of urban typography is a talkative behavior and becomes a problem of urban psychology, and (2) interpretants tend to look urban typography in terms of subfunctions or content rather than the design of the typography itself.

\subsection{Recommendation}

Several recommendations for the benefit of future research, as follows:

1. This research still holds and provides an abundant database as a result of data analysis that can be developed into scientific writing independently.

2. Future research needs to involve urban institutions to build communication-relations in order for the aims and presence of urban typography is conceptually known clearly by interpretants, so there will be no problems in pragmatic studies.

3. The discussion of the first semiosis process (logical argumentation) needs to be continued with the second semiosis research, namely the exploration of relations between two triadic elements.

4. There is a need for a comprehensive discussion between first and second semiosis processes.

5. There is a need for a cross-sectional discussion between Peirce's semiotics and Saussure's semiology in one comprehensive study.

6. There are opportunities for research regarding talkative behavior from the side of urban psychology.

\section{ACKNOWLEDGMENT}

Author thanks BPPM of Engineering Faculty for providing financial support through the PNBP scheme for this research study.

\section{REFERENCES}

[1] Robert Venturi, D. S. Learning from Las Vegas: The Forgotten Symbolism of Architectural Form. Urban Life, 192 (1979).

[2] Vinegar, A. I am a Monument on Learning From Las Vegas. Cambridge: The MIT Press, 2008.

[3] American-Studies. Architectural Populism. (American-Studies, Penyunt.) Vol.14 (1973) 135-140. Taken on 0325,2018 , from http://www.jstor.org/stable/41969576 
[4] Braudy, L. The Hollywood Sign: Fantasy and Reality of an American Icon. New Haven: Yale Universiy Press, 2011.

[5] Christie D. Batson, B. G. The Foreclosure Crisis and Neighborhood Sentiments: Learning from Las Vegas.

Social Justice, Vol. 40 (Foreclosure Crisis in the United States) (2014) 28-47. Taken on 0325 , 2018, from http://www.jstor.org/stable/24361647

[6] Hellman, L. Learning from Las Vegas. Built Environment, Vol. 8 (1982) 267-271. Taken on 03 25, 2018, from http://www.jstor.org/stable/23286056

[7] Kong, A. Re: Learning from Las Vegas; between Digital and Urban Space. London: The Royal College of Art, 2013.

[8] Liwang, F. Latah: Penyakit, Kebiasaan, atau Budaya? Kompasiana. Jakarta, 24 June 2015.

[9] Noerhadi, T. H. Semiotika dan Filsafat. R. S. EKM Masinambow, Semiotik (page. 1-9). Depok: PPKB Lemlit UI, 2000.

[10] Chris Calori, D. V.-E. A Complete Guide to Creating Environmental Graphic Design Systems: Signage and Wayfinding Design (Second ed.). New Jersey: John Wiley \& Sons, Inc., 2015.

[11] Kusdiwanggo, Susilo. Makna Desain Tipografi Ruang Urban secara Semiotika dari Paradigma Pragmatisisme berdasarkan Proses Semiosis Pembentukan Interpretan di Kota Malang. Malang. Universitas Brawijaya, 2018. 